\title{
Methods in the Synthesis and Conversion of 2,5-Bis-(hydroxylmethyl)furan from Bio-derived 5-Hydroxymethylfurfural and its Great Potential in Polymerization
}

\begin{abstract}
Junhua Zhang, ${ }^{*, a, b}$ Ting Wang, ${ }^{\mathrm{b}}$ Xing Tang, ${ }^{\mathrm{b}}$ Lincai Peng, ${ }^{\mathrm{a}}$ Junnan Wei, ${ }^{\mathrm{b}}$ and Lu Lin ${ }^{\mathrm{b}}$
To meet increasing demands for alternatives to fossil-based chemicals, environment-friendly and renewable energy materials are of great importance. Biomass-derived 2,5-bis-(hydroxylmethyl)furan (BHMF) has the potential to partly substitute petroleum-based aromatic diols during polymerization. This paper summarizes recent research on the synthesis of BHMF by the reaction of hydrogen from biomass-based 5hydroxymethylfurfural through different reduction routes, including the Cannizzaro reaction, catalytic hydrogenation, and catalytic transfer hydrogenation. Applications of BHMF as a direct material and intermediate in fabricating polyurethane, self-healing materials, resins, and more, which utilize ring-opening, double-bond addition, and oxidation reactions, are discussed briefly. Additionally, the challenges and opportunities in the formation and application of BHMF in the future are discussed.
\end{abstract}

Keywords: 5-Hydroxymethylfurfural; 2,5-Bis-(hydroxylmethyl)furan; Catalytic transfer hydrogenation; Biomass-based polymer

Contact information: a: Faculty of Chemical Engineering, Kunming University of Science and Technology, Kunming 650500, China; b: College of Energy, Xiamen University, Xiamen 361005, China;

* Corresponding author: 15868138978@163.com

\section{INTRODUCTION}

The gradual exhaustion of petroleum resources and the environmental problems resulting from the excessive use of fossil resources pose a threat to the sustainable development of human society. Thus, more attention has focused on the utilization of renewable energy materials that could partly or even completely replace fossil products (Tarasov et al. 2015; Li et al. 2016a; Patel and Kumar 2016; Qin et al. 2016; Rudie et al. 2016). Today, the exploration of high-value chemicals produced from biomass resources is becoming one of the most important approaches to determining applications of renewable materials. Such technology has the advantages of a large scale, broad distribution, and high reproducibility.

Biomass resources are commonly considered to be abundant, and include cornstalk, wheat straw, rice straw, energy forest timber, etc. These plants consist of lignin, hemicellulose, and cellulose. Cellulose is a linear polymer that is composed of $\beta-1,4-$ glycosidic bonds and can be converted to 5-hydroxymethylfurfural (HMF) via acid hydrolysis followed by acid-catalyzed dehydration (van Putten et al. 2013). Because of its hydroxymethyl and formyl groups, HMF can be converted to a variety of high-value chemicals, such as 2,5-dimethylfuran (DMF) (Jae et al. 2013), 2,5-furandicarboxylic acid (FDCA) (Zhang et al. 2015), and 2,5-bis-(hydroxylmethyl)furan (BHMF) (Cai et al. 2014), via hydrogenation and oxidative dehydrogenation reactions (Fig. 1). 


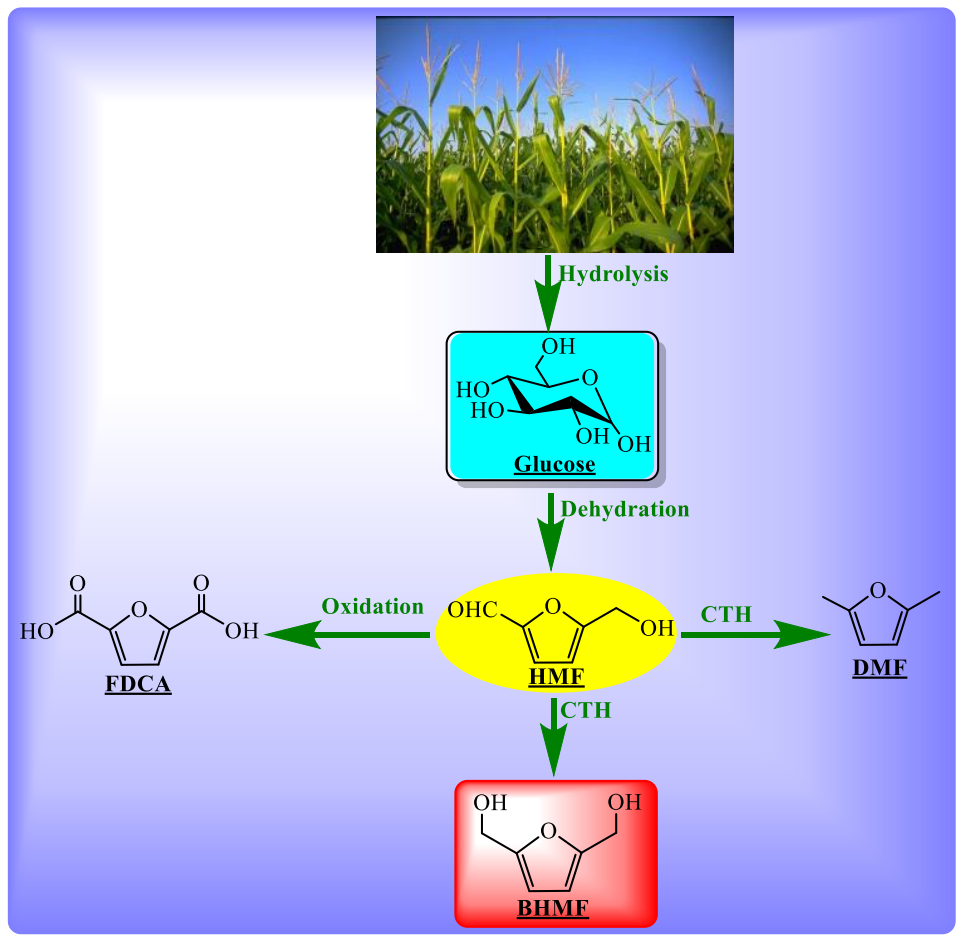

Fig. 1. Conversion of HMF to high-value chemicals; $\mathrm{CTH}$ : Catalytic transfer hydrogenation; this figure had been redrawn and is based on Wang et al. (2017).

An important biomass-derived chemical product is BHMF because it displays extensive application prospects that can be used to produce shape memory and self-healing polymers (Zeng et al. 2013a, 2013b, 2014). Meanwhile, BHMF can also be used as a structural monomer for the preparation of heat insulating materials (Cai et al. 2014), resins (Kang et al. 2012), and crown esters (Ohyama et al. 2013). Given its broad applications in biomass-based materials, it is of great importance to understand its synthesis and advances in applications. This paper summarizes the status of overseas and domestic research concerning the synthesis of BHMF from biomass-derived HMF. Additionally, the conversion of $\mathrm{BHMF}$ as a direct material and intermediate in hydrogenation, oxidation, and ring-opening reactions is discussed briefly. Moreover, the applications of BHMF in fabricating polyurethane, self-healing materials, resins, and other materials are discussed. Finally, the potential research direction of BHMF is contemplated.

\section{SYNTHESIS OF BHMF FROM HMF}

Previous reports have mainly utilized the Cannizzaro reaction, catalytic hydrogenation reaction, and catalytic transfer hydrogenation $(\mathrm{CTH})$ reduction reaction to synthesize BHMF from HMF.

\section{Cannizzaro Reaction}

The Cannizzaro reaction is commonly considered to be a disproportionation reaction. In general, both self-oxidative and self-reductive reactions of aldehyde without an $\alpha$-hydrogen atom, such as aliphatic aldehydes, aromatic aldehydes, and heterocyclic aldehydes, occur at the same time in a strong alkaline solvent. Then, homologous 
carboxylates and alcohols are generated. The HMF can be converted to BHMF via the Cannizzaro reaction (Fig. 2), which involves: 1) nucleophilic addition between alkali hydroxyl and carbonyl group of HMF to form tetrahedral-shaped intermediates; and 2) the transfer of hydride to a carbonyl carbon, to eventually generate BHMF and 5hydroxymethylfuranoic acid (HMFA).

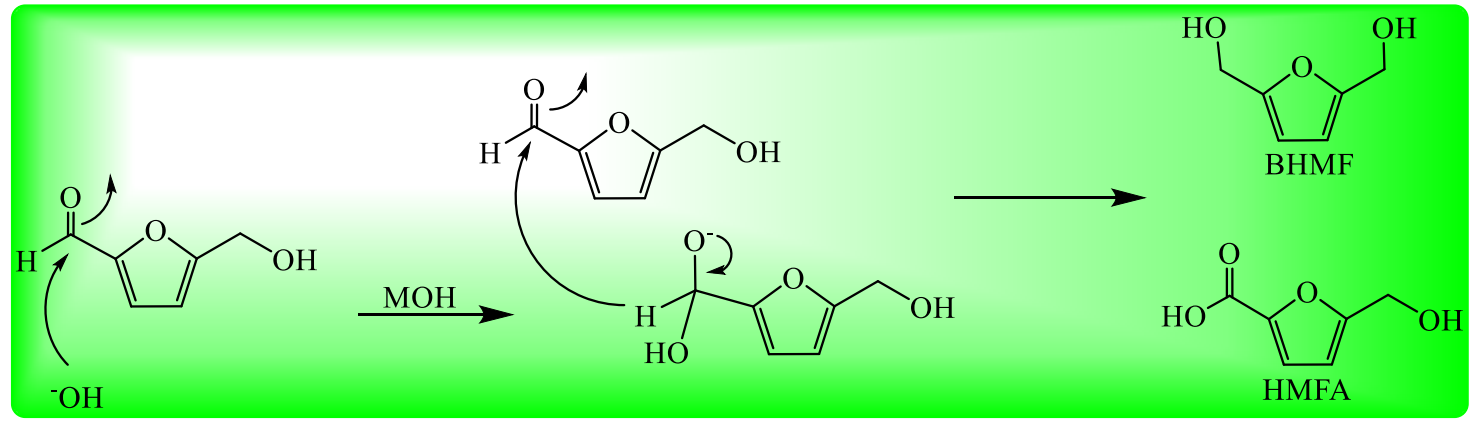

Fig. 2. Conversion of HMF to BHMF via Cannizzaro reaction (Kang et al. 2012)

Kang et al. (2012) studied the feasibility of BHMF synthesis with HMF via the Cannizzaro reaction in different ionic liquids (ILs). It was found that the yield of BHMF was related to the length of the alkyl chains (steric hindrance) and polarity of the ILs. Yields of 100\% BHMF and 84\% HMFA were obtained when using 1-ethyl-3-methylimidazolium bis(trifluoromethylsulfonyl)imide [EMIm]TFSI as the solvent. Moreover, a higher yield was obtained when using sodium hydroxide or potassium hydroxide as the hydroxyl donor because of their strong basicity, which is more in line with the conditions in the Cannizzaro reaction. Although ILs have been identified as an environmental green solvent and their catalytic effect has been shown to be excellent (Werner et al. 2010), their high price and difficult recovery operation affect their industrial applications.

The preparation of BHMF from HMF via the Cannizzaro reaction was also investigated by Subbiah et al. (2013) with a tetrahydrofuran (THF) system. A BHMF yield of up to $90 \%$ was obtained at $0{ }^{\circ} \mathrm{C}$ after $4 \mathrm{~h}$. However, the toxicity of the THF is incompatible with the current green chemistry concept. Additionally, THF can be easily converted to an explosive oxide in air conditions, which limits the use of this reaction system. Subbiah et al. (2013) used a sodium hydroxide solution as the solvent for the conversion of HMF to BHMF via the Cannizzaro reaction, and an $86 \%$ yield of BHMF was obtained at $0{ }^{\circ} \mathrm{C}$ after $18 \mathrm{~h}$ and the alkali solution could be recycled more than five times. The Cannizzaro reaction can obtain a mixture of BHMF and HMFA, where both have high yields. Therefore, the wide application of this method can be possibly promoted by the simplification of separation technology and the control of the technical cost.

\section{Catalytic Hydrogenation Reaction}

Hydrogen molecules adsorb onto a catalyst to attack weakened bonds, which causes the reduction reaction that is known as the catalytic hydrogenation reaction. This reaction can be used to catalyze HMF with metals or metal-metal oxide composites to prepare BHMF. And these metals or metal-metal oxide composites often can be treated with $\mathrm{NaBH}_{4}$ (Zeng et al. 2013; Sacia et al. 2014; Kieber et al. 2017). In this reaction system, deeply-reduced and ring-opening reactions most likely occur, which is shown in Fig. 3. The recent research concerning the catalytic hydrogenation reaction of HMF to BHMF is displayed in Table 1. 
Table 1. Chemoselective Hydrogenation of Biomass-derived HMF to BHMF with Different Catalysts

\begin{tabular}{|c|c|c|c|c|c|c|c|c|}
\hline Entry & Solvent & $\mathrm{H}_{2}$ & Catalyst & $T\left({ }^{\circ} \mathrm{C}\right)$ & $\begin{array}{c}t \\
(\mathrm{~h})\end{array}$ & $\begin{array}{c}\mathrm{HMF} \\
(\%)\end{array}$ & $\begin{array}{c}\mathrm{BHMF} \\
(\%)\end{array}$ & Reference \\
\hline 1 & $\begin{array}{l}\text { 1-Butanol- } \\
\text { water }\end{array}$ & $\begin{array}{l}400 \\
\text { psi }\end{array}$ & $\begin{array}{c}\mathrm{Ru} / \mathrm{MgO}- \\
\mathrm{ZrO}_{2}\end{array}$ & 130 & 2 & 99.0 & 93.1 & $\begin{array}{c}\text { (Alamillo et al. } \\
\text { 2012) }\end{array}$ \\
\hline 2 & Water & 5 bar & $\mathrm{Ru} / \mathrm{MSN}-\mathrm{Zr}$ & 25 & 4 & 98.1 & 90.4 & (Chen et al. 2013) \\
\hline 3 & Toluene & 10 bar & $\begin{array}{l}\text { Shvo's } \\
\text { catalyst }\end{array}$ & 90 & 1 & 100.0 & 99.0 & $\begin{array}{c}\text { (Pasini et al. } \\
\text { 2014b) }\end{array}$ \\
\hline 4 & $\begin{array}{l}\text { Toluene- } \\
\text { ethanol }\end{array}$ & 50 bar & $\begin{array}{l}\text { Cu-Ru- } \\
\text { PMO }\end{array}$ & 100 & 3 & 100.0 & 98.0 & $\begin{array}{c}\text { (Kumalaputri et al. } \\
2014)\end{array}$ \\
\hline 5 & n-alcohol & 15 bar & $\begin{array}{c}\mathrm{Ru}(\mathrm{OH}) \times / \mathrm{Zr} \\
\mathrm{O}_{2}\end{array}$ & 120 & 6 & $>99.0$ & $>99.0$ & (Han et al. 2016) \\
\hline 6 & Ethanol & $\begin{array}{r}200 \\
\text { psi }\end{array}$ & $\mathrm{PtSn} / \mathrm{Al}_{2} \mathrm{O}_{3}$ & 60 & 5 & 100.0 & 82.0 & $\begin{array}{c}\text { (Balakrishnan et al. } \\
\text { 2012) }\end{array}$ \\
\hline 7 & Water & 65 bar & $\mathrm{Au} / \mathrm{Al}_{2} \mathrm{O}_{3}$ & 120 & 2 & 100.0 & 96.0 & $\begin{array}{c}\text { (Ohyama et al. } \\
\text { 2013) }\end{array}$ \\
\hline 8 & Water & 8 bar & $\begin{array}{c}\mathrm{Ir}- \\
\mathrm{ReOx} / \mathrm{SiO}_{2}\end{array}$ & 30 & 6 & $>99.0$ & $>99.0$ & $\begin{array}{c}\text { (Tamura et al. } \\
2013)\end{array}$ \\
\hline 9 & Water & 60 bar & Ir- $\mathrm{TiO}_{2}$ & 50 & 3 & 99.5 & 95.4 & (Cai et al. 2014) \\
\hline 10 & Water & $\begin{array}{l}0.8 \\
\mathrm{MPa}\end{array}$ & Pt/MCM-41 & 35 & 2 & 100.0 & 98.9 & $\begin{array}{c}\text { (Chatterjee et al. } \\
2014)\end{array}$ \\
\hline 11 & Methanol & 25 bar & $\mathrm{Cu} / \mathrm{SiO}_{2}$ & 100 & 8 & 100.0 & 97.0 & (Cao et al. 2014) \\
\hline 12 & Ethanol & 50 bar & Cu-PMO & 100 & 3 & 100.0 & $>99.0$ & (Han et al. 2016) \\
\hline 13 & $\begin{array}{c}1,4- \\
\text { Dioxane }\end{array}$ & 15 bar & $\mathrm{Cu}-\mathrm{ZnO}$ & 100 & 2 & 100.0 & 99.1 & (Zhu et al. 2015) \\
\hline 14 & N-butanol & 30 bar & $\begin{array}{l}\mathrm{Ni}-\mathrm{Fe}- \\
\text { CNTs }\end{array}$ & 120 & 3 & 100.0 & 96.4 & (Yu et al. 2015) \\
\hline 15 & & 50 bar & NiFe-CFP & 150 & 20 & $>99.0$ & 88.0 & (Chieffi et al. 2014) \\
\hline 16 & Ethanol & 70 bar & Cu-Zn alloy & 120 & 3 & $>99.0$ & 95.0 & (Bottari et al. 2015) \\
\hline
\end{tabular}

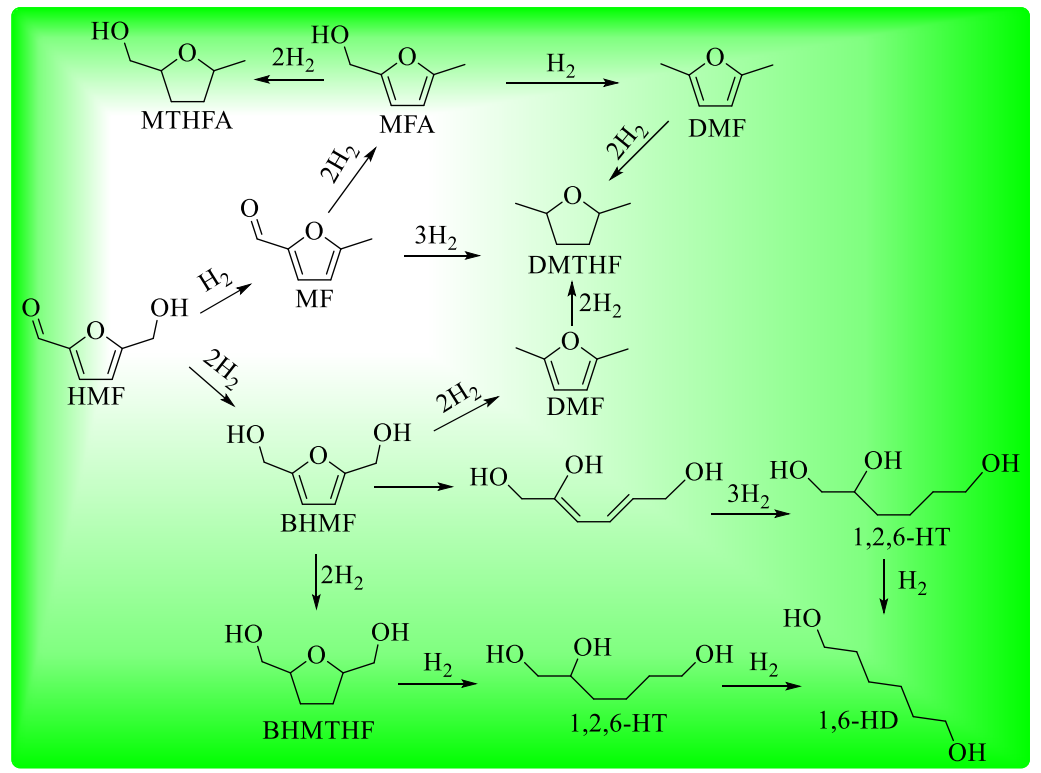

Fig. 3. Probable deeply-reduced, ring-opening products and other byproducts from the synthesis of BHMF from HMF; MF: 5-methylfurfural; MTHF: 5-methyltetrahydrofuran-2-carbaldehyde; MFA: 5-methylfurfural alcohol; DMTHF: 2,5-dimethyltetrahydrofuran; MTHFA: 5-methyltetrahydrofurfuryl alcohol; 1,2,6-HT: 1,2,6-hexanetriol; and 1,6-HD: 1,6-hexanediol (Buntara et al. 2011; Alamillo et al. 2012; Chatterjee et al. 2014) 


\section{Precious metal catalysts}

Recently, precious metal-based catalysts, such as Ru-, Ir-, Au-, and Pt-based catalysts, have been extensively used in the synthesis of BHMF and display relatively superior catalytic properties. Among them, Ru-based catalysts have received the most attention. It was reported by Alamillo et al. (2012) that the catalyst $\mathrm{Ru} / \mathrm{MgO}-\mathrm{ZrO} 2$ could be used for the reduction of HMF to BHMF and 2,5-bishydroxymethyltetrahydrofuran (BHMTHF). A selectivity as high as 94\% BHMF was demonstrated for $200 \mathrm{mg}$ of $\mathrm{Ru} / \mathrm{MgO}-\mathrm{ZrO}_{2}$ at $130{ }^{\circ} \mathrm{C}$ under 400 psi $\mathrm{H}_{2}$ after $2 \mathrm{~h}$. The selectivity of both BHMF and $\mathrm{BHMTHF}$ could be controlled by altering the $\mathrm{pH}$ value. An increasing selectivity of BHMF and decreasing selectivity of BHMTHF could be obtained by gradually increasing the $\mathrm{pH}$ value.

Chen et al. (2013) studied the nano-sized mesoporous $\mathrm{Ru}$ clusters supported by zirconium silica for the preparation of BHMF. The results demonstrated that the selectivity of BHMF from HMF was correlated to the particle size and electron deficiency of smallsized $\mathrm{Ru}$ clusters. Ru/MSN-Zr-20 with a particle size of $1.1 \mathrm{~nm}$ showed obvious hydrogenation activity of $\mathrm{HMF}$ under 5 bar $\mathrm{H}_{2}$ over $4 \mathrm{~h}$ at ambient temperatures. Additionally, the catalysts can be further utilized in the hydrogenation of a series of furan derivatives with a relatively high selectivity in furan alcohols. Also, the reusability experiments and calcination tests of $\mathrm{Ru} / \mathrm{MSN}-\mathrm{Zr}-20$ showed that this catalyst was very stable.

The Ru-based Shvo's catalysts were first utilized in the preparation of BHMF from HMF by Pasini et al. (2014b), and it was discovered that this catalyst can selectively promote the reduction of $\mathrm{C}=\mathrm{O}$ and $-\mathrm{NH}-$, as well as promoting the oxidation of $-\mathrm{OH}$ and $\mathrm{NH}_{2}$. Thus, the hydrogenolysis of $\mathrm{C}-\mathrm{O}$ and the addition of $\mathrm{C}=\mathrm{C}$ did not easily occur in the Shvo's system, which may have led to the efficient accumulation of BHMF. A BHMF selectivity of up to $99 \%$ was obtained at $90{ }^{\circ} \mathrm{C}$ under 10 bar $\mathrm{H}_{2}$ after $1 \mathrm{~h}$. In addition, the Shvo's catalysts could be recycled nine times while retaining a high catalytic effect. Tunable and selective conversion of $\mathrm{HMF}$ to $\mathrm{BHMF}$ was obtained with $\mathrm{Cu}_{20}-\mathrm{Ru}_{2}-\mathrm{PMO}$, for which the weight percentage of $\mathrm{Ru}$ at a low loading was only $0.6 \%$. Effectively, up to $98 \%$ BHMF was obtained at $100{ }^{\circ} \mathrm{C}$ under 50 bar $\mathrm{H}_{2}$ after $3 \mathrm{~h}$. Also, the deeply hydrogenation products of DMF and 2,5-dimethyltetrahydrofuran (DMTHF) (79\% in total) were obtained when the temperature was up to $220^{\circ} \mathrm{C}$.

Han et al. (2016) studied a wide variety of liquid reaction systems for the reduction of $\mathrm{HMF}$ to $\mathrm{BHMF}$ that used $\mathrm{Ru}(\mathrm{OH}) \mathrm{x} / \mathrm{ZrO}_{2}(0.3 \mathrm{~mol} \%$ of $\mathrm{Ru})$ as a catalyst. A BHMF selectivity of up to $99 \%$ was obtained at $120{ }^{\circ} \mathrm{C}$ under 15 bar $\mathrm{H}_{2}$ after $6 \mathrm{~h}$. The results showed that a high yield and turnover number (TON) value of BHMF could be obtained by using polar solutions as solvents, which was mainly because of the easy polarization of carbonyl groups; therefore, BHMF can be reduced in polar solutions. This result was consistent with that of Kang et al. (2012). Additionally, the theory of electron metal carrier interaction was verified by comparing the catalytic activity of different catalysts. A carrier metal oxide is helpful for improving the catalytic activity of metal catalysts (Herrmann 1985).

In addition to effective Ru-based catalysts, some other precious metal-based catalysts, such as Ir, Au, and Pt, have also been used for the preparation of BHMF. In the case of $\mathrm{Ir}-\mathrm{ReO}_{\mathrm{x}} / \mathrm{SiO}_{2}$, over $99 \%$ BHMF was obtained with at least $99 \%$ consumption of the $\mathrm{HMF}$ because of the synergy between the $\mathrm{Ir}$ and $\mathrm{ReO}_{\mathrm{x}}$. Specifically, the substrate adsorption and dissociation of $\mathrm{H}_{2}$ to ionic species were probably because of $\mathrm{ReO}_{\mathrm{x}}$, whereas a preferable TON and initial turnover frequency (TOF) were because of the surface metal 
Ir that contributed to a high selectivity without a decrease in the high activity (Tamura et al. 2013). Additionally, both metal species and the chemical supports played an important role in the activity of the catalysts. For instance, $\mathrm{Ir} / \mathrm{TiO}_{2}$ had a high selectivity (95.4\%) of BHMF and only $70 \%$ selectivity was obtained with $\mathrm{Ir} / \mathrm{C}$, which was attributed to the preference for carbonyl group hydrogenation of $\mathrm{TiO}_{2}$ (Cai et al. 2014). Gold sub-nano cluster-based catalysts generated a low selectivity of BHMF or even no selectivity $\left(\mathrm{Au} / \mathrm{ZrO}_{2}\right)$ with acidic metal oxide supports, while a BHMF selectivity of up to $96 \%$ was obtained when using $\mathrm{Au} / \mathrm{Al}_{2} \mathrm{O}_{3}$ (alkali metal oxide) as the catalyst at $120{ }^{\circ} \mathrm{C}$ under $3.8 \mathrm{MPa}$ $\mathrm{H}_{2}$ after $2 \mathrm{~h}$. In this reaction system, the selectivity of BHMF was not directly related to the $\mathrm{Au}$ element, but it was associated with the overall particle size direction of the $\mathrm{Au}$ clusters (Ohyama et al. 2013). Chatterjee et al. (2014) described the catalytic hydrogenation reduction systems catalyzed by combinations of various metals with MCM41 , and the $98.9 \%$ BHMF yield was obtained after catalyzation with Pt/MCM-41 at $35{ }^{\circ} \mathrm{C}$ under $0.8 \mathrm{MPa} \mathrm{H}_{2}$ for $2 \mathrm{~h}$. In this study, with a long time and high $\mathrm{H}_{2}$ pressure, further reduction reactions of the BHMF occurred, such as hydrogenolysis and ring-opening reactions. Both the HMF conversion and BHMF yield declined when an excess amount of deionized water was used to dilute the concentration of the reactants. The study also found that a neutral aqueous solution and negative $\delta$ values were more suitable for this reaction system compared with an acidic or alkaline aqueous solution and positive $\delta$ values. Balakrishnan et al. (2012) reported an $82 \% \mathrm{BHMF}$ yield after catalyzation with $\mathrm{PtSn} / \mathrm{Al}_{2} \mathrm{O}_{3}$ at $60{ }^{\circ} \mathrm{C}$ for $5 \mathrm{~h}$.

\section{Precious-metal-free catalysts}

The development of non-noble metal catalysts is of great importance for economic and industrial reasons. It has been reported that an extraordinary selectivity of BHMF ( $97 \%$ ) could be obtained after catalyzation with $\mathrm{Cu} / \mathrm{SiO}_{2}$, and etherification products could be further effectively derived from BHMF with different alcohols (Cao et al. 2014). Also, $\mathrm{Cu}_{20}$-PMO displayed an excellent selectivity for BHMF (99\%) at a mild reaction temperature $\left(100{ }^{\circ} \mathrm{C}\right)$, and its further hydrogenation products, such as DMF and DMTHF, could be observed with an increase in the temperature and reaction time (Kumalaputri et al. 2014).

Zhu et al. (2015) ascertained that $\mathrm{Cu} / \mathrm{Zn}$-based catalysts could promote the hydrogenolysis of $\mathrm{C}-\mathrm{O}$ at a high temperature with a long reaction time. It was also determined that the proportion of $\mathrm{Cu} / \mathrm{Zn}$ affects the catalytic efficiency, which was because of the change in its specific surface area, surface acid content, and surface $\mathrm{Cu}$ content. In the presence of $\mathrm{CuZn}-2$, a BHMF selectivity of up to $99.1 \%$ was obtained when using ethanol as the solvent at $100{ }^{\circ} \mathrm{C}$ after $2 \mathrm{~h}$. Additionally, CuZn-2 was used in the reduction of other furan compounds and showed a superior catalytic effect. The study also found that the selectivity of reaction products could be adjusted by altering the reaction temperature and time in accordance with the results of Tamura et al. (2013).

Additionally, Ni-Fe-CNTs have been used as a catalyst in the preparation of BHMF from HMF. At an atomic ratio of 2:1 (Ni:Fe), the Ni-Fe-CNT nanoparticles resulted in $100 \% \mathrm{HMF}$ conversion and a 96.1\% BHMF selectivity at $383 \mathrm{~K}$ after $18 \mathrm{~h}$. With an increasing loading of elemental $\mathrm{Fe}$, the hydrogenation ability was confined and the TOF correspondingly decreased, which contributed to the decrease in deeply-reduced products because of the interaction between the $\mathrm{Ni}$ and $\mathrm{Fe}$. In addition to the formation of a Ni-Fe alloy, the products distribution between BHMF and its over-reduced products was partly determined by the reaction temperature and time (Yu et al. 2015). Compared with Ni-Fe- 
CNTs, FeNi-CFP displayed a relatively moderate catalytic effect at $150{ }^{\circ} \mathrm{C}$ under 50 bar $\mathrm{H}_{2}$ (Chieffi et al. 2014). A similar catalytic selectivity (95\%) was observed in the case of nano-sized $\mathrm{Cu}-\mathrm{Zn}$ alloy catalysts at a mild temperature (Bottari et al. 2015).

\section{Catalytic Transfer Hydrogenation Reduction}

The reaction of CTH reduction uses hydrogen-containing polyatomic molecules as hydrogen donors, and it has the potential to replace the traditional hydrogenation reaction with $\mathrm{H}_{2}$ as the hydrogen donor for the preparation of BHMF. Only a few reports have focused on the $\mathrm{CTH}$ reduction of HMF to BHMF, and the hydrogen donors used in the studies were formic acid (FA), methanol, ethanol, and isopropanol.

The donor FA can provide a mild condition for the CTH reduction of HMF to BHMF, which can completely preclude ring hydrogenation. In the presence of FA, a $94 \%$ BHMF yield was obtained in refluxing THF after $4 \mathrm{~h}$ with $\mathrm{Pd} / \mathrm{C}$. In addition to $\mathrm{H}_{2} \mathrm{SO}_{4}$, a two-step hydrogenolysis reaction occurred to form DMF with methyl formate as the intermediate (Thananatthanachon and Rauchfuss 2010a). Thananatthanachon and Rauchfuss (2010b) also demonstrated the CTH reduction of HMF to BHMF with $\mathrm{Cp} * \operatorname{Ir}(\mathrm{TsDPEN}-\mathrm{H})$, and $99 \% \mathrm{BHMF}$ was yielded at $40{ }^{\circ} \mathrm{C}$ after $2 \mathrm{~h}$ with FA as the hydrogen donor. It has also been reported that the catalyst $\mathrm{Cp} * \operatorname{Ir}(\mathrm{TsDPEN})$ is appropriate in a one-pot process to generate BHMF from fructose in the presence of extra base.

Recently, some alcohols were also used to generate BHMF via CTH reduction, which has a selectivity for the hydrogenation of the carbonyl groups. Under relatively mild conditions with a high yield of BHMF, few deeply-reduced products and almost no ringopening products were obtained compared with traditional hydrogenation. Hao et al. (2016) studied the preparation of BHMF from HMF via the CTH reaction in the presence of ethanol.

At $423 \mathrm{~K}$ and after $2.5 \mathrm{~h}$, a 94.1\% HMF conversion and $88.9 \%$ BHMF yield were obtained after catalyzation with $\mathrm{ZrO}(\mathrm{OH})_{2}$, and the principal byproducts were its etherification products. Additionally, it was indicated that the electronegativity and steric hindrance of $\mathrm{ZrO}(\mathrm{OH})_{2}$ had a great effect on the $\mathrm{HMF}$ conversion and BHMF yield. The catalytic effect apparently declined with an increase in the recovery time because of a large amount of carbon deposits on the catalyst surface. Carbon deposits on catalysts and the suitability of a single alcohol in the reaction system can greatly influence the wide application of a catalyst (Han et al. 2016).

Wang et al. (2017) researched the synthesis of BHMF from HMF via the CTH reaction in the presence of the catalyst $\mathrm{Ru} / \mathrm{Co}_{3} \mathrm{O}_{4}$. It was determined that this reaction contained several main steps. First, isopropanol is activated by the $\mathrm{Ru} / \mathrm{Co}_{3} \mathrm{O}_{4}$ catalyst to form a ruthenium hydride, which is then broken down to $\mathrm{Ru}-\mathrm{H}$ and acetone. Second, the generated $\mathrm{Ru}-\mathrm{H}$ reacts with the HMF to form transition complex I, and then transition complex II is generated through a five-membered transition state. Finally, BHMF is generated with the elimination of the ruthenium hydride, and a small amount of BHMF can be further hydrogenated to 5-methylfurfuryl alcohol through the CTH route under very strong reaction conditions (Fig. 4). The results showed that the conversion of HMF was as high as $100 \%$ and the yield of BHMF was up to $82.5 \%$ at $190{ }^{\circ} \mathrm{C}$ after $6 \mathrm{~h}$. Moreover, the catalyst recovery experiments showed that the conversion of HMF was $95.3 \%$ and the yield of BHMF was $75.2 \%$. Therefore, the final efficiency of the catalyst recovery was up to $94 \%$. 


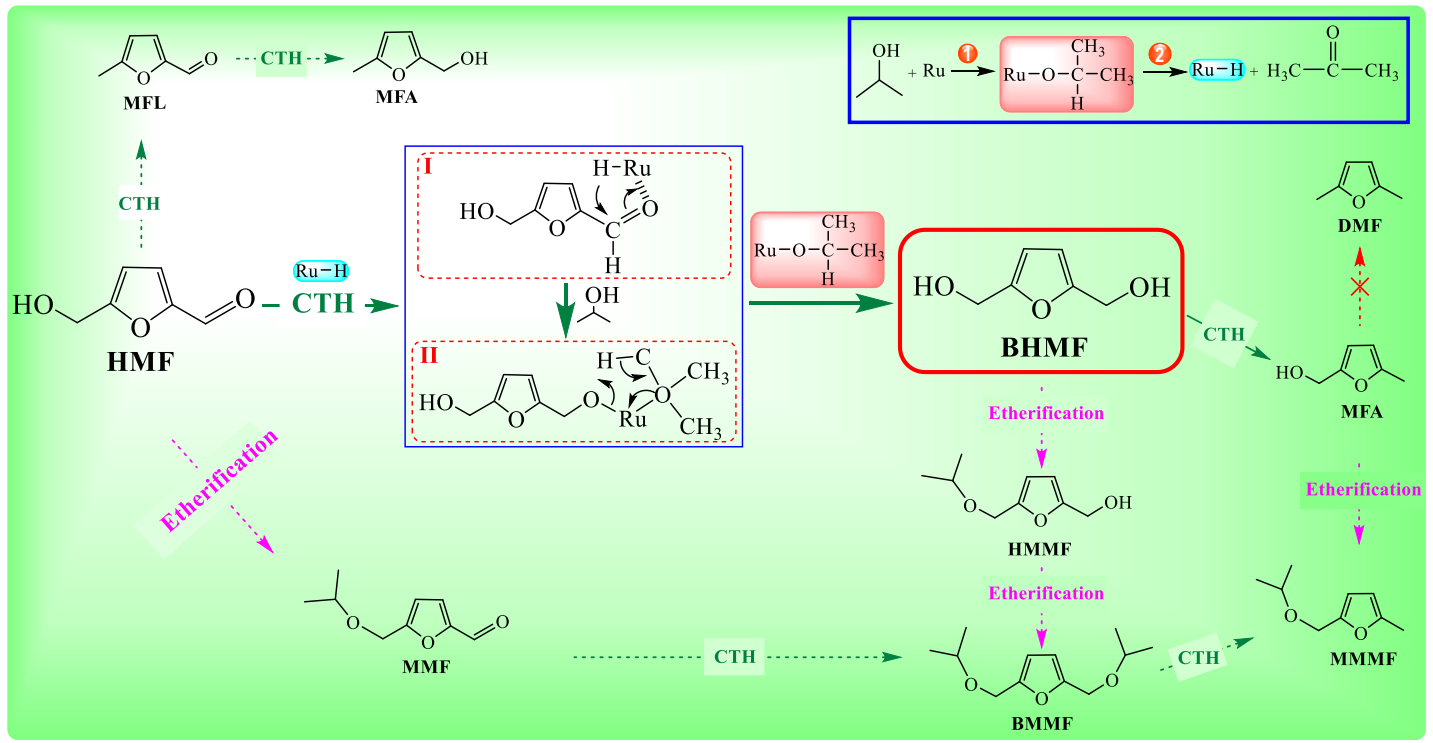

Fig. 4. Proposed reaction pathways of the $\mathrm{CTH}$ reduction of $\mathrm{HMF}$ to $\mathrm{BHMF}$ using an isopropanol and $\mathrm{Ru} / \mathrm{Co}_{3} \mathrm{O}_{4}$ reaction system; MMF: 5-[(1-methylethoxy) methyl] furfural; HMMF: 5hydroxymethyl-2-[(1-methylethoxy)methyl]furan; BMMF: 2,5-[bis(1-methylethoxy)-methyl]furan; MMMF: 2-methyl-5-[(1-methyletyoxy)methyl]furan; and MFL: 5-methyl furfural (Johnstone et al. 1985; Guiral et al. 2001; Wang et al. 2017)

Methanol has also been utilized to synthesize BHMF from HMF over high-surface area $\mathrm{MgO}$, and resulted in a total conversion of $\mathrm{HMF}$ and a simplex generation of BHMF at $160{ }^{\circ} \mathrm{C}$ after $3 \mathrm{~h}$. The final byproducts were some gaseous products that could be easily separated from the liquid phase (Pasini et al. 2014a).

The chemical 1,4-butanediol has been used as a hydrogen donor for the CTH reduction of HMF to BHMF. It was reported by Aellig et al. (2014) that hydrogen was generated through a lactonization reaction in a continuous flow reactor. The generated hydrogen was then used as the hydrogen donor for the reduction of HMF to BHMF. As a result, yields of 93\% BHMF and 28\% $\gamma$-butyrolactone (GBL) with a conversion of $93 \%$ $\mathrm{HMF}$ and $29 \%$ 1,4-butanediol were obtained at $220{ }^{\circ} \mathrm{C}$ after $0.6 \mathrm{~min}$. By increasing the residence time to $29 \mathrm{~min}$, hydrogenolysis products and a higher GBL yield were obtained.

\section{CURRENT AND POTENTIAL APPLICATIONS OF BIO-DERIVED BHMF}

As an important bio-derived chemical, BHMF has a wide range of applications in many areas. Both conjugated double bonds and two hydroxymethyl groups are present in BHMF, which can react with substituted olefins during Diels-Alder reactions and undergo esterification-polycondensation with carboxylic acids. Additionally, BHMF can react with imino compounds or diols to form high polymerization degree polymers. In this paper, the polymerization of BHMF with the various reaction mechanisms mentioned above was discussed. Ring-opening reactions, double-bond addition, and oxidation of BHMF, as a direct material and intermediate, were also briefly discussed. 


\section{Deep-reactions of BHMF}

The deep reactions of BHMF discussed in this paper mainly include ring-opening reactions that generate 1,6-hexanediol (1,6-HD) and 1,2,6-hexanetriol (1,2,6-HT), doublebond addition reactions that generate BHMTHF, and oxidation reactions that produce $\alpha-6$ hydroxy-6-methyl-4-enyl-2H-pyran-3-on.

The chemical 1,6-HD is commonly considered as a platform chemical for synthesizing polymers, which can generate polyurethane, adhesives, plasticizers, and other materials (Figueiredo et al. 2008). Recently, some research has studied the synthesis of 1,6-HD via multi-step approaches with BHMTHF as an intermediate. Buntara et al. (2011) comparatively studied a variety of approaches to synthesize 1,6-HD from HMF, including a one-step method and several multi-step approaches (Fig. 5). When HMF is directly reduced to $1,6-\mathrm{HD}$, the reaction conditions are relatively harsh and the amount of byproducts increases, which in turn increases the difficulty of separation. However, with multi-step reactions, where HMF is first reduced to BHMTHF and then to 1,6-HD through different routes, the reaction conditions become relatively mild and the overall selectivity is improved. It has also been reported that the double-layered catalysts $\mathrm{Pd} / \mathrm{SiO}_{2}$ and Ir$\mathrm{ReO}_{\mathrm{x}} / \mathrm{SiO}_{2}$ can be employed for the synthesis of 1,6-HD from HMF with BHMTHF as an intermediate (Zhang et al. 2017). In the presence of water and THF, 57.8\% 1,6-HD was obtained at a relatively high $\mathrm{H}_{2}$ pressure, which suppressed over-hydrolysis reactions. To a certain extent, BHMTHF can also be synthesized with BHMF (Chen et al. 2015). Hence, the preparation of 1,6-HD from BHMF with BHMTHF as an intermediate was possibly achieved with mild conditions and few byproducts.

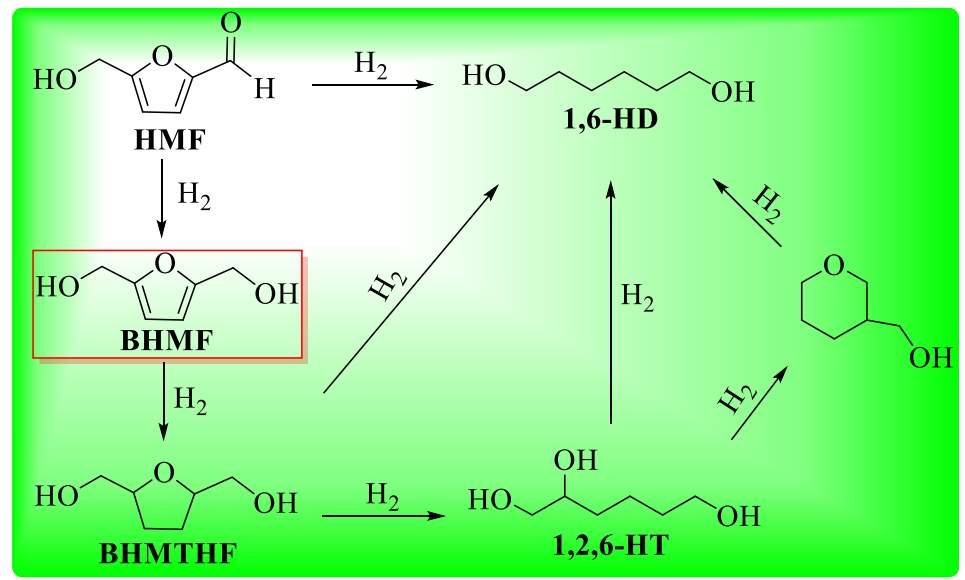

Fig. 5. Synthesis routes for 1,6-HD from HMF or BHMF (Buntara et al. 2011)

The chemical BHMF is also an important intermediate for the synthesis of 1,2,6HT from bio-based HMF, which can be used in the pharmaceuticals and cosmetics industries, and in resins and plastics as a humectant, solvent, and viscosity-controlling agent. The mechanism for the ring-opening reactions of HMF is shown in Fig. 6 and is as follows: 1) HMF is quickly hydrogenated to BHMF, 2) the furan ring of BHMF is adsorbed onto the catalysts in the parallel or tilted modes to generate BHMTHF, and 3) the BHMTHF obtained via the tilted mode undergoes a ring-opening reaction to generate 1,2,6-HT (Yao et al. 2014). Until now, some multi-metallic catalysts (Co-Al, Ni-Co-Al, and $\mathrm{Ni}-\mathrm{Al}$ mixed oxide catalysts) have been employed in the synthesis of 1,2,6-HT from bio-based HMF. Because of the interaction between elemental $\mathrm{Co}$ and $\mathrm{Ni}, 1,2,6-\mathrm{HT}$ was effectively obtained 
at a yield of $64.5 \%$ at $120{ }^{\circ} \mathrm{C}$ and $4 \mathrm{MPa} \mathrm{H}_{2}$ with $\mathrm{BHMF}$ as an intermediate. Apart from the above reaction, $\mathrm{Rh}-\mathrm{ReOx} / \mathrm{SiO}_{2}$ has also been employed in the conversion of $\mathrm{HMF}$ to 1,2,6-HT, where 1,2,6-HT can be obtained with BHMTHF as an intermediate. At $120{ }^{\circ} \mathrm{C}$, 80 bar $\mathrm{H}_{2}$, and after $4 \mathrm{~h}$, a conversion of $31 \% \mathrm{HMF}$ with an $84 \%$ BHMF selectivity was obtained (Buntara et al. 2013).

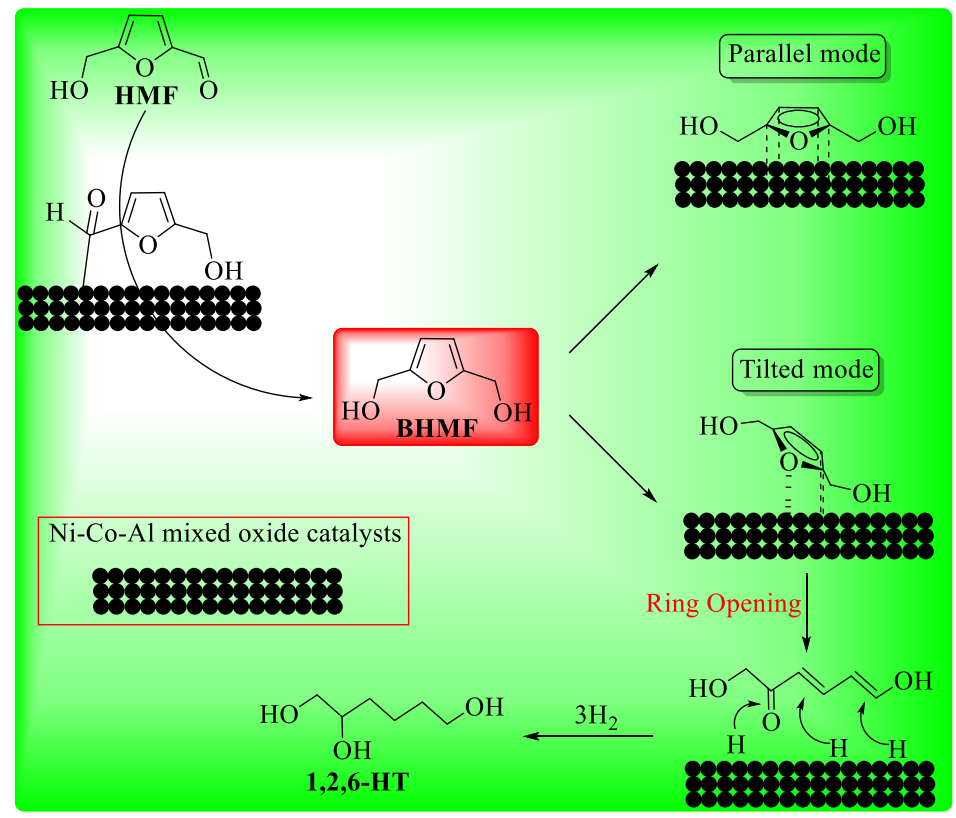

Fig. 6. Synthetic mechanism of 1,2,6-HT from HMF with BHMF as an intermediate (Yao et al. 2014)

Double-bond addition and oxidation reactions of BHMF can generate BHMTHF, which is a precursor of various high-value monomers and solvents (Chatterjee et al. 2014). Some studies have investigated the production of BHMTHF from HMF with BHMF as an intermediate product. The influence of the catalyst supports with different surface areas or isoelectric points, the solvent system, and different metal-based catalysts have been discussed in detail. It has also been reported that the oxidation product $\alpha$ - 6 -hydroxy-6methyl-4-enyl-2H-pyran-3-on is generated when using BHMF as the raw material, and a $45 \%$ yield was obtained at $70{ }^{\circ} \mathrm{C}$ after 30 min when Amberlyst 15 was used as the catalyst (Gelmini et al. 2016). The product obtained represented an attractive preparation of bioactive compounds, and is a step forward in the field of generating biopharmaceuticals from biomass.

\section{Polymerization of BHMF}

Because of the multifunctional groups in BHMF, including hydroxyls and double bonds of carbon, BHMF can be converted to various products through different reaction mechanisms (Fig. 7). Polyurethanes (PUs) are one of the most well-known polymer materials available. They have a wide range of properties for numerous applications due to their excellent performance properties, imparted by the urethane linkages, as well as facile tailoring of properties by the choice of starting compounds and synthetic conditions. Hightech applications of PUs can be achieved, where novel and additional features, such as wettability, adhesion, conductivity, biological activity, catalysis and anti-oxidization, are required (Nguyen et al. 2013). 


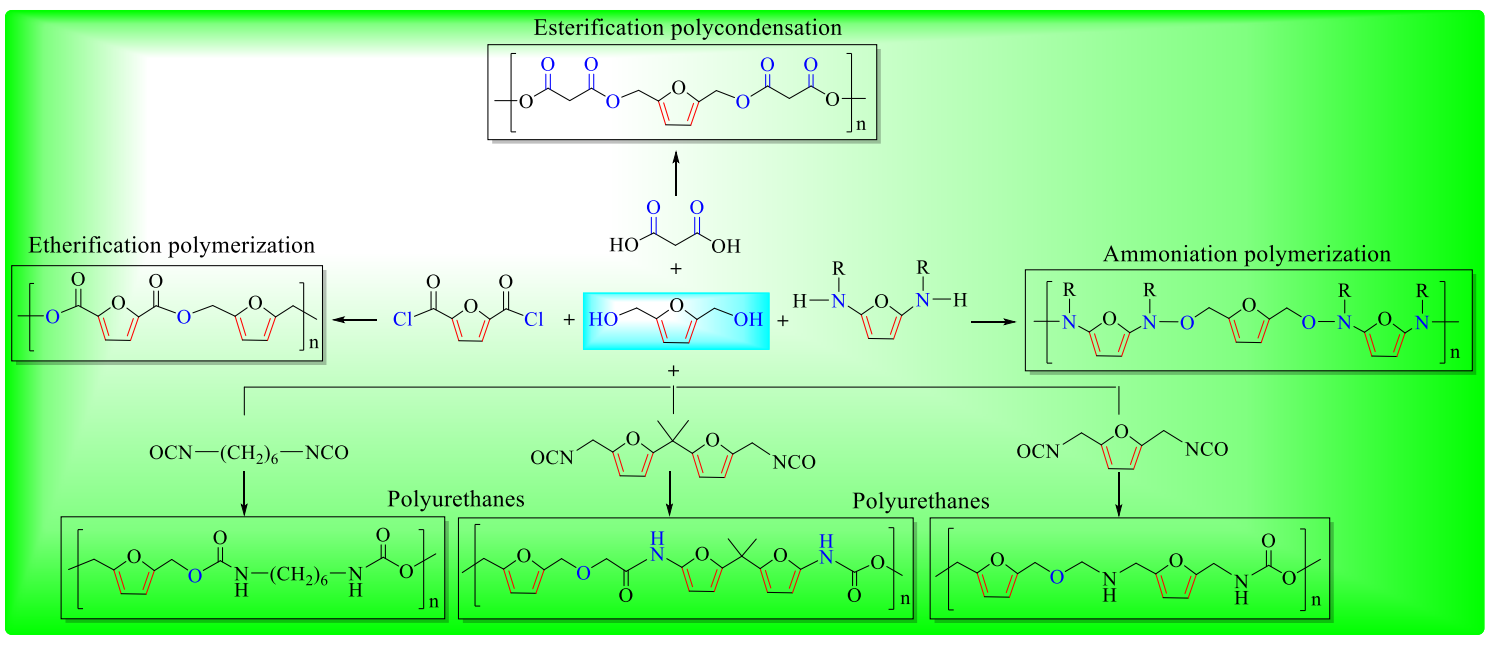

Fig. 7. Polymerization of bio-based BHMF to various products: etherification, esterification, ammoniation, and polyurethanes products (Amarasekara 2011; Kieber et al. 2017)

Based on the stringent requirements of the surface properties of polyurethane materials, Nguyen et al. (2013) performed a series of chemical coupling modifications of polyurethane materials and used BHMF as a coupling monomer. Various "click" and coupling reactions, consisting of copper(I) catalyzed Huisgen 1,3-dipolar alkyne-azide, thermally and photo-initiated thiolene/thiolyne, and Diels-Alder reactions, have been used for surface functionalization of polyurethane foams. And the coupling conversion extent of BHMF was increased by increasing the amount of the copolymer maleimide. Moreover, the reaction time positively correlated with the coupling conversion of BHMF, while the reactant concentration, which correspondingly induced diffusion, was negatively linked with the same conversion. Thus, in light of these results, the surface properties of polyurethane materials can eventually be improved by adjusting the factors mentioned above to the best reaction point.

The compound BHMF and succinic acid (SA) can also be used for the preparation of self-healing polymers, which are new materials that can heal themselves when damaged. When these kinds of healing materials are broken, relatively weak dynamic bonds at the broken surfaces tend to dissociate. Because of the reversibility of dynamic bonds, they can be reformed to recover the shape and properties of the materials. Zeng et al. (2013b) stated that the preparation of a furan polymer, poly(2,5-furandimethylene succinate), one of the self-healing materials can be divided into two parts: 1) the esterification polymerization between BHMF and succinic acid, and 2) the Diels-Alder reactions between the former products and 1,8-bis(maleimido)-triethylene glycol $\left(\mathbf{M}_{2}\right)$ (Fig. 8). In general, with an increase in the ratio of BHMF to $\mathrm{M}_{2}$, the healing ability of the materials is enhanced. Based on the above research, Ikezaki et al. (2014) studied a similar reaction system, but used 1,4butanediol as a co-monomer. Self-healing materials can be also obtained, and the results were in good agreement with the aforementioned study (Zeng et al. 2013a). Zeng et al. (2013b) also studied the self-healing ability of materials in different solvents and in the presence of BHMF. To some extent, the self-healing ability depends upon the bond length between the two dienophiles for Diels-Alder reaction and the flexibility of the bonds. With an increasing length and feasibility of connection keys $\left(\mathrm{M}_{2}\right)$, the self-healing ability is enhanced, which is due to the increased crosslink density induced as a function of increase $\mathrm{M}_{2}$. Multiple shape memory materials were studied by Zeng et al. (2014) in a similar system. To control the memory temperature, the glass transition temperature of the 
materials was altered by changing the concentration of the $\mathbf{M}_{2}$ solvent. This strategy achieved a certain breakthrough in the flexibility and diversity of shape memory materials.

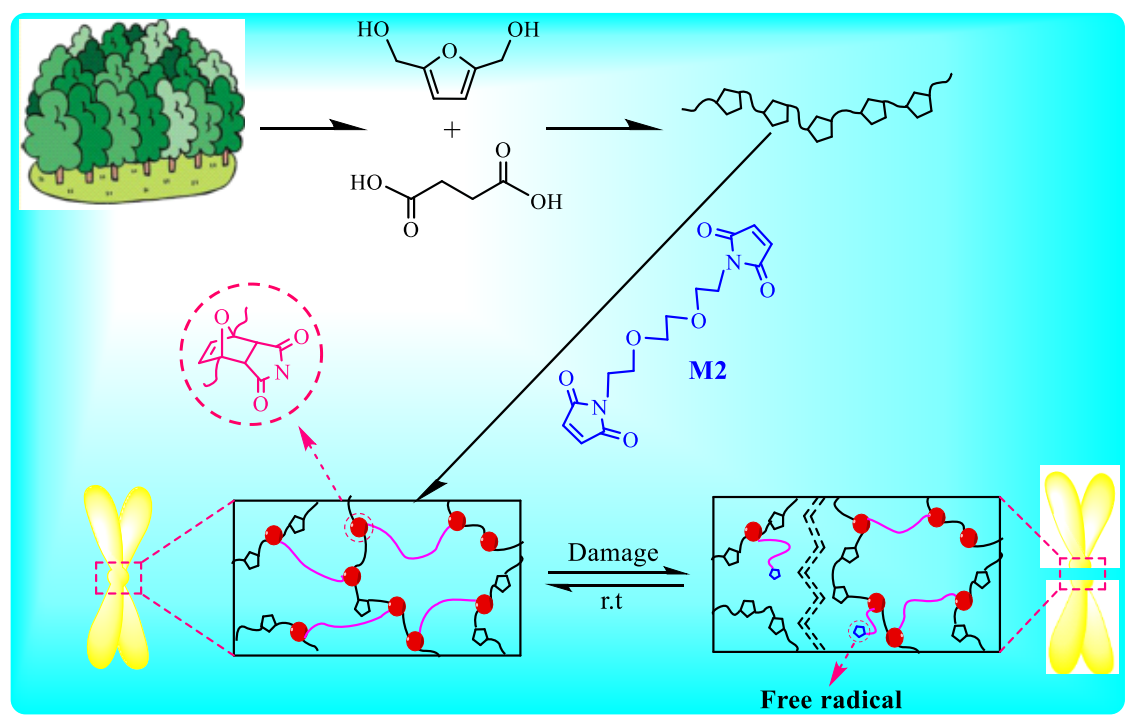

Fig. 8. Proposed synthesis pathways of self-healing materials with the co-monomer BHMF (Zeng et al. 2013a)

Recently, BHMF was effectively applied in the synthesis of epoxy resins. Compared with phenyl-based epoxy resins, furan-based epoxy resins displayed much better thermodynamic performances with lower viscosities and higher glass transition temperatures and storage moduli. The main reasons for those results may have been that the furan ring is less flexible and its hydrogen bonding force is noticeably enhanced during the curing process (Hu et al. 2016). However, the reference to $\mathrm{Hu}$ et al. (2016) put out a correction that mentions that incorrect stoichiometry was used in their previous report. Due to this, their finding of a higher glass transition temperature $\left(T_{\mathrm{g}}\right)$ for the BHMF based resin over the phenol was incorrect; the phenolic resin actually exhibited slightly higher $T_{\mathrm{g}}$. Li et al. (2016b) analyzed the influence of furan rings on furan-based epoxy resins via molecular simulation technology. The results showed that a higher bulk density between the furan-based epoxy resins had a great effect on the flexibility of the polymer, which then affected its thermodynamic performance. Only a few reports have focused on the extended applications of BHMF-based resins. Golino (1996) studied the effect of BHMF-based resins on the binding force between glass fibers. To obtain a favorable viscosity and hardness, the furfural resins and phenolic resins were mixed with BHMF-based resins, and the expansion rate of the modified resins increased and the flammability of the resins correspondingly decreased.

Moreover, free radical polymerization and enzymatic polymerization reactions can also occur in the presence of BHMF. Fawcett et al. (1987) studied the free radical polymerization reaction between BHMF and acrylonitrile. It was found that the degradation temperature of the product dropped remarkably if the product obtained still contained hydroxyl groups. Jiang et al. (2014) studied enzymatic polymerization reactions with BHMF. The research results were as follows: 1) the increase in glass transition temperature for furanic polyesters $v s$. aliphatic polyesters at lower molecular weights is primarily due to the additional rigidity of the backbone; 2) the crystallinity and crystallization rate of the polyesters correlated with the methylene chain length; and 3) if 
the obtained polyesters had more methylene, that is if the molecular chain was much longer, the thermal stability of the furan-based polyesters became noticeably better.

In addition to the above, crown ethers using multi-numbers of BHMF as monomers can be obtained by the treatment of tetraethyleneglycol ditosylate. Polyethers that are BHMF-based can also be generated with either dihalides or diols in the case of a phasetransfer catalyst. Boufi et al. (1997) studied the polymerization of various compounds with hydroxyl functional groups, including BHMF. When increasing the molar amount of $\mathrm{BHMF}$, molecular weight of the polymers increased correspondingly; that is, the degree of polymerization increased. Generally, the hydroxyl functional groups had a positive effect on the polymerization reactions in the absence of interference from the catalysts and ions. Additionally, the influence of different solvent systems on the reactions was also demonstrated by the hydroxyl functional groups. The highest yield was obtained when using nitromethane as the solvent, which was probably because nitromethane is a polarized acidic solution and a polar solvent is beneficial to the polarization of hydroxyl groups. This made it easier for the reaction to occur. In addition, polycarbonates have been prepared via an approach similar to the one given above for ethers. Gopalakrishnan et al. (2014) polymerized BHMF with adipic acid to form an amorphous polymer, and the products had a glass transition temperature of approximately $50{ }^{\circ} \mathrm{C}$.

\section{CONCLUSIONS}

This paper provides an overview and insight for readers concerning the preparation of biomass-derived BHMF from biomass-based platform chemicals and its potential applications. Three different approaches to synthesize BHMF were discussed. Among them, the $\mathrm{CTH}$ reaction was elaborated on in detail, as the $\mathrm{CTH}$ reaction has the advantage of high selectivity and no need for fossil-based hydrogen donors.

Then, the applications of BHMF in the field of polymerization, such as in the fabrication of polyurethane, self-healing materials, and resins, were discussed because the compound contains double bonds and two hydroxymethyl groups. Moreover, the ringopening reactions, double-bond addition, and oxidation of $\mathrm{BHMF}$, as a direct material and intermediate, were also briefly reviewed.

\section{ACKNOWLEDGMENTS}

This work was financially supported by the National Natural Science Foundation of China (21406208), Natural Science Foundation of Zhejiang Province (LY17C160008), Open Foundation of the Most Important Subjects in Colleges and Universities in Zhejiang Province (2015YXQN13), Zhejiang Provincial Top Key Academic Discipline of Chemical Engineering and Technology of Zhejiang Sci-Tech University (YR2015005), and 521 Talent Cultivation Program of Zhejiang Sci-Tech University (11110132521309).

\section{REFERENCES CITED}

Aellig, C., Jenny, F., Scholz, D., Wolf, P., Giovinazzo, I., Kollhoff, F., and Hermans, I. (2014). "Combined 1,4-butanediol lactonization and transfer hydrogenation/ 
hydrogenolysis of furfural-derivatives under continuous flow conditions," Catal. Sci. Technol. 4(8), 2326-2331. DOI: 10.1039/C4CY00213J

Alamillo, R., Tucker, M., Chia, M., Pagán-Torres, Y., and Dumesic, J. (2012). “The selective hydrogenation of biomass-derived 5-hydroxymethylfurfural using heterogeneous catalysts," Green Chem. 14(5), 1413-1419. DOI: 10.1039/C2GC35039D

Amarasekara, A. S. (2011). "5-Hydroxymethylfurfural based polymers," Renewable Polymers , Mittal, V., Ed. John Wiley \& Sons, 381-428. DOI: 10.1002/9781118217689.ch9

Balakrishnan, M., Sacia, E. R., and Bell, A. T. (2012). "Etherification and reductive etherification of 5-(hydroxymethyl)furfural: 5-(Alkoxymethyl)furfurals and 2,5bis(alkoxymethyl)furans as potential bio-diesel candidates," Green Chem. 14(6), 1626-1634. DOI: 10.1039/C2GC35102A

Bottari, G., Kumalaputri, A. J., Krawczyk, K. K., Feringa, B. L., Heeres, H. J., and Barta, K. (2015). "Copper-zinc alloy nanopowder: A robust precious-metal-free catalyst for the conversion of 5-hydroxymethylfurfural," ChemSusChem 8(8), 1323-1327. DOI: $10.1002 /$ cssc. 201403453

Boufi, S., Belgacem, M. N., and Gandini, A. (1997). "2-Furyloxiranes III. Chain extension with different polyols," Polym. J. 29(6), 479-486. DOI: 10.1295/polymj.29.479

Buntara, T., Melián-Cabrera, I., Tan, Q., Fierro, J. L. G., Neurock, M., de Vries, J. G., and Heeres, H. J. (2013). "Catalyst studies on the ring opening of tetrahydrofurandimethanol to 1,2,6-hexanetriol," Catal. Today 210, 106-116. DOI: 10.1016/j.cattod.2013.04.012

Buntara, T., Noel, S., Phua, P. H., Melián-Cabrera, I., de Vries, J. G., and Heeres, H. J. (2011). "Caprolactam from renewable resources: Catalytic conversion of 5-hydroxymethylfurfural into caprolactone," Angew. Chem. Int. Edit. 50(31), 7083-7087. DOI: 10.1002/anie. 201102156

Cai, H., Li, C., Wang, A., and Zhang, T. (2014). "Biomass into chemicals: One-pot production of furan-based diols from carbohydrates via tandem reactions," Catal. Today 234, 59-65. DOI: 10.1016/j.cattod.2014.02.029

Cao, Q., Liang, W., Guan, J., Wang, L., Qu, Q., Zhang, X., Wang, X., and Mu, X. (2014). "Catalytic synthesis of 2,5-bis-methoxymethylfuran: A promising cetane number improver for diesel," Appl. Catal. A-Gen. 481, 49-53. DOI:

10.1016/j.apcata.2014.05.003

Chatterjee, M., Ishizaka, T., and Kawanami, H. (2014). "Selective hydrogenation of 5hydroxymethylfurfural to 2,5-bis-(hydroxymethyl)furan using Pt/MCM-41 in an aqueous medium: A simple approach," Green Chem. 16(11), 4734-4739. DOI: 10.1039/C4GC01127A

Chen, J., Liu, R., Guo, Y., Chen, L., and Gao, H. (2015). "Selective hydrogenation of biomass-based 5-hydroxymethylfurfural over catalyst of palladium immobilized on amine-functionalized metal-organic frameworks," ACS Catal. 5(2), 722-733. DOI: $10.1021 / \operatorname{cs} 5012926$

Chen, J., Lu, F., Zhang, J., Yu, W., Wang, F., Gao, J., and Xu, J. (2013). “Immobilized $\mathrm{Ru}$ clusters in nanosized mesoporous zirconium silica for the aqueous hydrogenation of furan derivatives at room temperature," ChemCatChem 5(10), 2822-2826. DOI: $10.1002 /$ cctc. 201300316 
Chieffi, G., Giordano, C., Antonietti, M., and Esposito, D. (2014). "FeNi nanoparticles with carbon armor as sustainable hydrogenation catalysts: Towards biorefineries," $J$. Mater. Chem. A 2(30), 11591-11596. DOI: 10.1039/C4TA02457E

Fawcett, A. H., Yau, T. F., Mulemwa, J. N., and Tan, C. E. (1987). “The free-radically prepared copolymers of acrylonitrile with furfuryl alcohol and similar furan derivatives," Polym. Int. 19(2), 211-221. DOI: 10.1002/pi.4980192014

Figueiredo, F. C. A., Jordão, E., and Carvalho, W. A. (2008). "Adipic ester hydrogenation catalyzed by platinum supported in alumina, titania and pillared clays," Appl. Catal. A-Gen. 351(2), 259-266. DOI: 10.1016/j.apcata.2008.09.027

Gelmini, A., Albonetti, S., Cavani, F., Cesari, C., Lolli, A., Zanotti, V., and Mazzoni, R. (2016). "Oxidant free one-pot transformation of bio-based 2,5-bis-hydroxymethylfuran into alpha-6-hydroxy-6-methyl-4-enyl-2H-pyran-3-one in water," Appl. Catal. B-Environ. 180, 38-43. DOI: 10.1016/j.apcatb.2015.06.003

Golino, C. M. (1996). "Glass fiber binding compositions, process of binding glass fibers, and glass fiber compositions," U. S. Patent No. EP0642476B1.

Gopalakrishnan, P., Narayan-Sarathy, S., Ghosh, T., Mahajan, K., and Belgacem, M. N. (2014). "Synthesis and characterization of bio-based furanic polyesters," J. Polym. Res. 21(1), 340. DOI: 10.1007/s10965-013-0340-0

Guiral, V., Delbecq, F., and Sautet, P. (2001). "Origin of the enantioselectivity in the hydrogen transfer reduction of carbonyls by a rhodium(I) complex: A theoretical study," Organometallics 20(11), 2207-2214. DOI: 10.1021/om010120v

Han, J., Kim, Y.-H., Jang, H.-S., Hwang, S.-Y., Jegal, J., Kim, J. W., and Lee, Y.-S. (2016). "Heterogeneous zirconia-supported ruthenium catalyst for highly selective hydrogenation of 5-hydroxymethyl-2-furaldehyde to 2,5-bis(hydroxymethyl)furans in various $n$-alcohol solvents," RSC Adv. 6(96), 93394-93397. DOI:

10.1039/C6RA18016G

Hao, W., Li, W., Tang, X., Zeng, X., Sun, Y., Liu, S., and Lin, L. (2016). “Catalytic transfer hydrogenation of biomass-derived 5-hydroxymethyl furfural to the building block 2,5-bishydroxymethyl furan," Green Chem. 18(4), 1080-1088. DOI: 10.1039/C5GC01221J

Herrmann, J.-M. (1985). "Electronic effects in strong metal-support interactions on titania-deposited metal catalysts: Reply to F. Solymosi's comments," J. Catal. 94(2), 587-589. DOI: 10.1016/0021-9517(85)90228-3

Hu, F., La Scala, J. J., Sadler, J. M., and Palmese, G. R. (2016). “Correction to synthesis and characterization of thermosetting furan-based epoxy systems," Macromolecules 49(6), 2408-2408. DOI: 10.1021/acs.macromol.5b02801

Ikezaki, T., Matsuoka, R., Hatanaka, K., and Yoshie, N. (2014). "Biobased poly(2,5furandimethylene succinate-co-butylene succinate) crosslinked by reversible DielsAlder reaction," J. Polym. Sci. Pol. Chem. 52(2), 216-222. DOI: 10.1002/pola.26990

Jae, J., Zheng, W., Lobo, R. F., and Vlachos, D. G. (2013). "Production of dimethylfuran from hydroxymethylfurfural through catalytic transfer hydrogenation with ruthenium supported on carbon," ChemSusChem 6(7), 1158-1162. DOI:

$10.1002 /$ cssc. 201300288

Jiang, Y., Woortman, A. J. J., Van Ekenstein, G. O. R. A., Petrović, D. M., and Loos, K. (2014). "Enzymatic synthesis of biobased polyesters using 2,5-bis(hydroxymethyl) furan as the building block," Biomacromolecules 15(7), 2482-2493. DOI: $10.1021 / \mathrm{bm} 500340 \mathrm{w}$ 
Johnstone, R. A. W., Wilby, A. H., and Entwistle, I. D. (1985). "Heterogeneous catalytic transfer hydrogenation and its relation to other methods for reduction of organic compounds," Chem. Rev. 85(2), 129-170. DOI: 10.1021/cr00066a003

Kang, E.-S., Chae, D. W., Kim, B., and Kim, Y. G. (2012). "Efficient preparation of DHMF and HMFA from biomass-derived HMF via a Cannizzaro reaction in ionic liquids," J. Ind. Eng. Chem. 18(1), 174-177. DOI: 10.1016/j.jiec.2011.11.020

Kieber, R. J., Silver, S. A., and Kennemur, J. G. (2017). "Stereochemical effects on the mechanical and viscoelastic properties of renewable polyurethanes derived from isohexides and hydroxymethylfurfural," Polym. Chem-UK 33(8), 4822-4829. DOI: 10.1039/C7PY00949F

Kumalaputri, A. J., Bottari, G., Erne, P. M., Heeres, H. J., and Barta, K. (2014). "Tunable and selective conversion of 5-HMF to 2,5-furandimethanol and 2,5-dimethylfuran over copper-doped porous metal oxides," ChemSusChem 7(8), 2266-2275. DOI: 10.1002/cssc. 201402095

Li, H., Xia, S., Luo, H., and Ma, P. (2016a). "Experimental and computational study on the compatibility of biodiesel/diesel/methanol blended fuel," Fuel 173, 52-59. DOI: 10.1016/j.fuel.2016.01.036

Li, K., Huo, N., Liu, X., Cheng, J., and Zhang, J. (2016b). "Effects of the furan ring in epoxy resin on the thermomechanical properties of highly cross-linked epoxy networks: A molecular simulation study," RSC Adv. 6(1), 769-777. DOI: 10.1039/C5RA22955C

Nguyen, L.-T. T., Devroede, J., Plasschaert, K., Jonckheere, L., Haucourt, N., and Du Prez, F. E. (2013). "Providing polyurethane foams with functionality: A kinetic comparison of different "click" and coupling reaction pathways," Polym. Chem. 4(5), 1546-1556. DOI: 10.1039/C2PY20970E

Ohyama, J., Esaki, A., Yamamoto, Y., Arai, S., and Satsuma, A. (2013). "Selective hydrogenation of 2-hydroxymethyl-5-furfural to 2,5-bis(hydroxymethyl)furan over gold sub-nano clusters," RSC Adv. 3(4), 1033-1036. DOI: 10.1039/C2RA22190J

Pasini, T., Lolli, A., Albonetti, S., Cavani, F., and Mella, M. (2014a). "Methanol as a clean and efficient H-transfer reactant for carbonyl reduction: Scope, limitations, and reaction mechanism," J. Catal. 317, 206-219. DOI: 10.1016/j.cat.2014.06.023

Pasini, T., Solinas, G., Zanotti, V., Albonetti, S., Cavani, F., Vaccari, A., Mazzanti, A., Ranieri, S., and Mazzoni, R. (2014b). "Substrate and product role in the Shvo's catalyzed selective hydrogenation of the platform bio-based chemical 5-hydroxymethylfurfural," Dalton T. 43(26), 10224-10234. DOI: 10.1039/C4DT00304G

Patel, M., and Kumar, A. (2016). "Production of renewable diesel through the hydroprocessing of lignocellulosic biomass-derived bio-oil: A review," Renew. Sust. Energ. Rev. 58, 1293-1307. DOI: 10.1016/j.rser.2015.12.146

Qin, Y., Yu, L., Wu, R., Yang, D., Qiu, X., and Zhu, J. Y. (2016). "Biorefinery lignosulfonates from sulfite-pretreated softwoods as dispersant for graphite," ACS Sustain. Chem. Eng. 4(4), 2200-2205. DOI: 10.1021/acssuschemeng.5b01664

Rudie, A. W., Houtman, C. J., Groom, L. H., Nicholls, D. L., and Zhu, J. Y. (2016). "A survey of bioenergy research in forest service research and development," Bioenerg. Res. 9(2), 534-547. DOI: 10.1007/s12155-016-9731-5

Sacia, E. R., Balakrishnan, M., and Bell, A. T. (2014). "Biomass conversion to diesel via the etherification of furanyl alcohols catalyzed by Amberlyst-15," J. Catal. 313, 7079. DOI: $10.1016 /$ j.jcat.2014.02.012 
Subbiah, S., Simeonov, S. P., Esperança, J. M. S. S., Rebelo, L. P. N., and Afonso, C. A. M. (2013). "Direct transformation of 5-hydroxymethylfurfural to the building blocks 2,5-dihydroxymethylfurfural (DHMF) and 5-hydroxymethyl furanoic acid (HMFA) via Cannizzaro reaction," Green Chem. 15(10), 2849-2853. DOI: 10.1039/C3GC40930A

Tamura, M., Tokonami, K., Nakagawa, Y., and Tomishige, K. (2013). "Rapid synthesis of unsaturated alcohols under mild conditions by highly selective hydrogenation," Chem. Commun. 49(63), 7034-7036. DOI: 10.1039/C3CC41526K

Tarasov, D., Leitch, M., and Fatehi, P. (2015). "Production of lignosulfonate in NSSCbased biorefinery," Biotechnol. Progr. 31(6), 1508-1514. DOI: 10.1002/btpr.2149

Thananatthanachon, T., and Rauchfuss, T. B. (2010a). "Efficient production of the liquid fuel 2,5-dimethylfuran from fructose using formic acid as a reagent," Angew. Chem. Int. Edit. 49(37), 6616-6618. DOI: 10.1002/anie.201002267

Thananatthanachon, T., and Rauchfuss, T. B. (2010b). "Efficient route to hydroxymethylfurans from sugars via transfer hydrogenation," ChemSusChem 3(10), 1139-1141. DOI: $10.1002 /$ cssc.201000209

Van Putten, R-J., van der Waal, J. C., de Jong, E., Rasrendra, C. B. Heeres, H. J., and de Vries, J. G. (2013). "Hydroxymethylfurfural, a versatile platform chemical made from renewable resources," Chem. Rev. 113(3), 1499-1597. DOI: 10.1021/cr300182k

Werner, S., and Wasserscheid, P. (2010). "Ionic liquids in chemical engineering," Annu. Rev. Chem. Biomol. 1(1), 203-230. DOI: 10.1146/annurev-chembioeng-073009100915

Wang, T., Zhang, J., Xie, W., Tang, Y., Guo, D., and Ni, Y. (2017). "Catalytic transfer hydrogenation of biobased HMF to 2,5-bis-(hydroxymethyl)furan over $\mathrm{Ru} / \mathrm{Co}_{3} \mathrm{O}_{4}$," Catalysts 7(3), 92. DOI: 10.3390/catal7030092

Yao, S., Wang, X., Jiang, Y., Wu, F., Chen, X., and Mu, X. (2014). “One-step conversion of biomass-derived 5-hydroxymethylfurfural to 1,2,6-hexanetriol over Ni-Co-Al mixed oxide catalysts under mild conditions," ACS Sustain. Chem. Eng. 2(2), 173180. DOI: $10.1021 / \mathrm{sc} 4003714$

Yu, L., He, L., Chen, J., Zheng, J., Ye, L., Lin, H., and Yuan, Y. (2015). "Robust and recyclable nonprecious bimetallic nanoparticles on carbon nanotubes for the hydrogenation and hydrogenolysis of 5-hydroxymethylfurfural," ChemCatChem 7(11), 1701-1707. DOI: 10.1002/cctc.201500097

Zeng, C., Seino, H., Ren, J., Hatanaka, K., and Yoshie, N. (2013a). "Bio-based furan polymers with self-healing ability," Macromolecules 46(5), 1794-1802. DOI: $10.1021 / \mathrm{ma} 3023603$

Zeng, C., Seino, H., Ren, J., Hatanaka, K., and Yoshie, N. (2013b). "Self-healing biobased furan polymers cross-linked with various bis-maleimides," Polymer 54(20), 5351-5357. DOI: 10.1016/j.polymer.2013.07.059

Zeng, C., Seino, H., Ren, J., and Yoshie, N. (2014). "Polymers with multishape memory controlled by local glass transition temperature," ACS Appl. Mater. Inter. 6(4), 2753 2758. DOI: 10.1021/am405287p

Zhang, J., Li, J., Tang, Y., Lin, L., and Long, M. (2015). “Advances in catalytic production of bio-based polyester monomer 2,5-furandicarboxylic acid derived from lignocellulosic biomass," Carbohyd. Polym. 130, 420-428. DOI: 10.1016/j.carbpol.2015.05.028

Zhang, Y., Li, T., Xie, Z., Han, J., Xu, J., and Guo, B. (2017). "Synthesis and properties of biobased multiblock polyesters containing poly(2,5-furandimethylene succinate) 
and poly(butylene succinate) blocks," Ind. Eng. Chem. Res. 56(14), 3937-3946. DOI: 10.1021/acs.iecr.7b00516

Zhu, Y., Kong, X., Zheng, H., Ding, G., Zhu, Y., and Li, Y.-W. (2015). "Efficient synthesis of 2,5-dihydroxymethylfuran and 2,5-dimethylfuran from 5-hydroxymethylfurfural using mineral-derived $\mathrm{Cu}$ catalysts as versatile catalysts," Catal. Sci. Technol. 5(8), 4208-4217. DOI: 10.1039/C5CY00700C

Article submitted: January 25, 2018; Peer review completed: April 22, 2018; Revised version received and accepted: May 18, 2018; Published: May 27, 2018.

DOI: 10.15376/biores.13.3.Zhang 